creasing level of mathematical sophistication", it is appropriate to consider presenting the second law of thermodynamics to them through Carathéodory's formulation: and this chapter outlines the way in which this can be done. Interesting and stimulating though this is, I wonder whether it really is appropriately included in this treatise ; and, if so, why it should have been relegated to the end.

In all, I approach this book with mixed feelings. There is a need to bring together the various branches of physical chemistry and in particular to point the way to new applications of thermodynamics. And because few scientists today have the time to write encyclopaedic textbooks, multi-author volumes of the present kind seem inevitable. Yet when they do little more, as in parts of this volume, than to reproduce the core material of standard textbooks, I wonder whether an annotated reading list would not have been almost as useful -and would have left more room for a fuller treatment of more sophisticated topics: it is for this material that the book will be most useful.

The production is excellent, as we expect from this publisher, and few errors (except the interchanging of Figures 17 and 18 of chapter 2) were noted.

\section{H. EVERETT}

\section{Crystallography}

Methods in X-ray Crystallography. By J. W. Jeffrey. Pp. xxix + 571. (Academic: London and New York, December 1971.) £11.50; $\$ 35$.

According to the jacket, the main aim of this book is to cover the techniques required for the interpretation of singlecrystal X-ray diffraction in detail, up to the production of observed structure factors for use in structural analysis. The book can be divided into four approximately equal parts; the first develops the basic theory, the second describes the construction and use of every kind of X-ray camera, the third consists of ten appendices (including one on radiation safety devices), and the fourth is devoted to forty-two exercise examples and their detailed solutions.

A more accurate title would be "Photographic Methods in X-ray Crystallography", for the emphasis throughout is almost entirely upon photographic techniques. The more commonly used counter methods for intensity measurement (in a recent number of Acta Crystallographica, Section B, about $70 \%$ of the structures were determined with counters) receive only one or two rather fleeting references. Professor Jeffery is well known as a devotee of photographic methods,

\title{
Candled Ice Surface
}

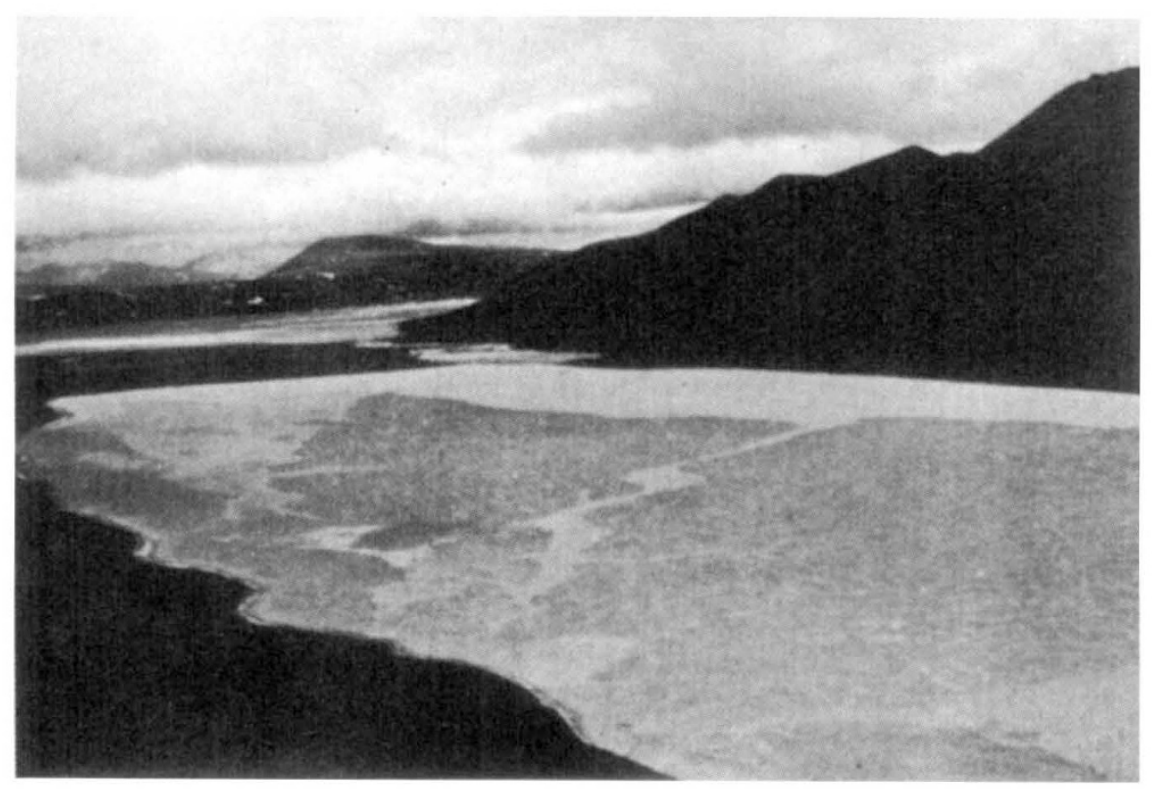

Crystalline structure of ice on Peters Lake, Alaska. Where the ice looks light coloured, the $c$ axes of the crystals are vertical; dark ice has horizontal $c$ axes. The photograph, originally published by the International Glaciological Society in the Journal of Glaciology, is reproduced in chapter 12, "Fracture of lake and sea ice", of Fracture: An Advanced Treatise, edited by Harold Liebowitz (Academic Press, New York and London, 1972). This volume, Volume 7, deals with nonmetals and composites.

and his enthusiasm and flair come over strongly. The reproductions of all kinds of X-ray photographs are quite superb. The student would take a very long time to be able to produce photographs of this high quality, but the book certainly tells him all he could possibly need to know in order to do so.

The needs of students new to the subject are well catered for by the inclusion of "Students' Notes" (which provide a guide to the use of the book), a comprehensive and definitive list of symbols, and appendices covering basic mathematics. But Professor Jeffrey has possibly been a little over-solicitous in places-for example in the passage dealing with centring of crystals on camera axes.

The bibliography is rather scant, there being only twenty-two references to books and papers. Inevitably in a work of this magnitude, there are a few minor blemishes such as wrongly numbered equations, incorrect references to appendices and the consistent mis-spelling of Cochran. But the presentation is attrac. tive, the treatment sympathetic and the work should be of considerable benefit to students.

J. P. G. RICHARDS

\section{Scattering of Atoms}

The Calculation of Atomic Collision Processes. By Kenneth Smith. Pp. $x+218$. (Wiley: New York and London, April 1972.) $\quad £ 5.50$.

Scattering Theory: The Quantum Theory on Nonrelativistic Collisions. By John R. Taylor. Pp. xvi +477 . (Wiley: New York and London, August 1972.) $£ 6.75$.

A WELCOME addition to the literature, Professor Smith's book should be of particular use to the postgraduate student interested in atomic-collision theory. It is divided into Part 1 , an introductory course, and Part 2, a more advanced course which might benefit any active researcher in atomic physics.

Although one calculates numbers as against processes, the title is accurately descriptive. The author's conviction is that models in theoretical physics must be put to the quantitative test. The emphasis on the algebra and numerical analysis of the algorithmic approach is appropriate, whether to electron-atom, atom-atom or electron-molecule collisions. Taken in conjunction with Computer Physics Communications, the student is presented with ample scope for experimental projects on the computer.

Of course, physical understanding does not always come from studying heavy algebra: the physics is often to be found in the various complex planes. The physical interpretation of zeroes and poles in the complex energy (or linearmomentum) plane therefore strikes a 